\title{
Effectiveness and petroleum geological significance of tectonic fractures in the ultra-deep zone of the Kuqa foreland thrust belt: a case study of the Cretaceous Bashijiqike Formation in the Keshen gas field
}

\author{
Rong-Hu Zhang ${ }^{1,2} \cdot \mathrm{Ke} \mathrm{Wang}^{2} \cdot$ Qing-Lu Zeng $^{1} \cdot$ Chao-Feng Yu ${ }^{1} \cdot$ Jun-Peng Wang ${ }^{1}$
}

Received: 12 July 2020 / Accepted: 26 November 2020 / Published online: 9 June 2021

(c) The Author(s) 2021

\begin{abstract}
The buried depth of the gas-producing reservoir in the Kuqa foreland thrust belt of the Tarim Basin exceeds $6000 \mathrm{~m}$. The average matrix porosity of the reservoir is $5.5 \%$, and the average matrix permeability is $0.128 \times 10^{-3} \mu \mathrm{m}^{2}$. In order to reveal the characteristics and effectiveness of ultra-deep fractures and their effects on reservoir properties and natural gas production, outcrops, cores, thin section, image logs and production testing data are used to investigate the effectiveness of tectonic fractures in ultra-deep reservoirs in the Kuqa foreland thrust zone, and the corresponding geological significance for oil and gas exploration and development are discussed. Tectonic fractures in the thrust belt include EW-trending high-angle tensile fractures and NS-trending vertical shear fractures. The former has a relatively high filling rate, while the latter is mostly unfilled. Micro-fractures are usually grain-piercing-through cracks with width of 10-100 microns. In the planar view, the effective fractures are concentrated in the high part and wing zones of the long axis of the anticline, and along the vertical direction, they are mainly found in the tensile fracture zone above the neutral plane. The adjustment fracture zone has the strongest vertical extension abilities and high effectiveness, followed by the nearly EW longitudinal tensile fracture zone, and the netted fracture zone with multiple dip angles. The effectiveness of fracture is mainly controlled by fracture aperture and filling degrees. Effective fractures can increase reservoir permeability by 1-2 orders of magnitude. The higher part of the anticline is associated with high tectonic fracture permeability, which control enrichment and high production of natural gas. The netted vertical open fractures effectively communicate with pores and throats of the reservoir matrix, which forms an apparent-homogenous to medium-heterogeneous body that is seen with high production of natural gas sustained for a long term.
\end{abstract}

Keywords Fracture effectiveness $\cdot$ Ultra-deep $\cdot$ Reservoir $\cdot$ Foreland thrust belt $\cdot$ Kuqa depression $\cdot$ Geological significance

\section{Introduction}

Tight sandstone gas is an important unconventional hydrocarbon resource (Jia et al. 2012; Guo et al. 2013; Dai et al. 2012; Zhang et al. 2014; Yang et al. 2018; Zhang et al.

Edited by Jie-Hao and Chun-Yan Tang

Rong-Hu Zhang

zrh_hz@petrochina.com.cn

1 PetroChina Research Institute of Petroleum Exploration and Development, Beijing 100086, China

2 PetroChina Hangzhou Research Institute of Geology, Hangzhou 310023, Zhejiang, China
2014; Li et al. 2012; Zeng 2009; Zhan et al. 2017; Zeng et al. 2012). The strong compaction effect (including both normal burial compaction and abnormal structural compression) results in low matrix porosity $(<10 \%)$ and low permeability (air permeability $<1 \times 10^{-3} \mu \mathrm{m}^{2}$ or overburden permeability $<0.1 \times 10^{-3} \mu \mathrm{m}^{2}$ ) in tight sandstone reservoirs, therefore an industrial-scale natural gas reservoir cannot be formed by the rock matrix porosity alone (Fossen 2010; Orlando et al. 2010; Solum et al. 2010; Lander and Laubach 2015; Ju et al. 2014). The presence of tectonic fractures is a very important factor for improving the physical properties of tight sandstone reservoirs and increasing natural gas productivity (Ding et al. 2015; Zeng et al. 2010a, b; Estibalitz et al. 2016; Feng et al. 2018). Therefore, the systematic study 
of the effectiveness of tectonic fractures in tight sandstone reservoirs is of great significance for discovering tight sandstone sweet spot and improving gas reservoir productivity (Kara et al. 2017; Lander and Laubach 2015; Nian et al. 2017).

The Keshen gas field is located in the deep zone of the Kelasu tectonic belt in the Kuqa depression, the Tarim Basin, and its target formation, the Lower Cretaceous Bashijiqike Formation, is a typical ultra-deep $(>6000 \mathrm{~m}$ ) naturally fractured tight sandstone reservoir (Wang 2014; Zeng et al. 2008; Lai et al. 2017a). Regarding the foreland thrust belt of the Kuqa depression and the tectonic fractures in Keshen gas field, numerous studies have carried out in various aspects before, including quantitative description and prediction of fractures (Zeng and Wang 2014; Zhao et al. 2014; Wang et al. 2014; Lai et al. 2019), indicative implications of regional stress field inversion provided by fractures (Zhang and Wang 2004; Zeng et al. 2004), formation mechanisms of fractures and influential factors (Zeng et al. 2010a, b; Liu et al. 2017; Chang et al. 2014; Gong et al. 2015). These studies have revealed that fractures lead to obvious modification of ultra-deep tight sandstone reservoirs (Wang et al. 2018). The Cretaceous Bashijiqike Formation is found with extensive development of tectonic fractures, which controls high productivity of natural gas in the Keshen gas field. In this paper, on the basis of analysis of tectonic fracture types and characteristics as well as information obtained from cores, thin sections and image logs, the effectiveness of tectonic fractures is studied, with the aim to provide geological guidance on the efficient development of the Keshen gas field.

\section{Geological settings}

The Tarim Basin is the biggest petroliferous basin in China (Lai et al. 2020), and a large number of giant gas fields have been found in the Kuqa depression recently ( $\mathrm{Ju}$ and Wang 2018). In this paper, the study area-the Keshen gas field is located in the Kelasu tectonic belt of the Kuqa depression, the Tarim Basin, which is rich in natural gas resources, with multiple faulted anticline gas reservoirs such as $\mathrm{KeS} 5, \mathrm{KeS6}, \mathrm{KeS} 2, \mathrm{KeS} 8, \mathrm{KeS} 9$, and $\mathrm{KeS} 13$ (Fig. 1). The proven geological reserves of natural gas exceed $10,000 \times 10^{8} \mathrm{~m}^{3}$ (Wang 2014). The gas-bearing target layer of the Keshen gas field is the Bashijiqike Formation of the Lower Cretaceous, which is mainly composed of reddish brown fine sandstone, siltstone, medium sandstone and thin mudstone, with burial depths of 5500-8500 $\mathrm{m}$, an average thickness of about $300 \mathrm{~m}$, matrix porosity of $1.5 \%-5.5 \%$, and matrix permeability of $(0.01-0.1) \times$ $10^{-3} \mu \mathrm{m}^{2}$ (Zhang et al. 2014). Data from cores and image logs indicate that tectonic fractures with a density higher than $0.3 \mathrm{~m}^{-1}$ have developed in the Bashijiqike Formation. The physical property measurements of fractured cores show that the permeability provided by fractures is of $(0.1-10.0) \times 10^{-3} \mu \mathrm{m}^{2}$, which suggests a typical lowporosity naturally fractured tight sandstone reservoir.

\section{Tectonic fracture characteristics}

The observation of core and interpretation of FMI image logs indicate that there are both tensile and shear fractures developing in the Keshen gas field. The fracture surface of the tensile fracture is crooked unevenly, with an aperture of $0.5-1 \mathrm{~mm}$, and the tensile fractures are mostly highangle fractures, filled with calcite, dolomite or anhydrite. Moreover, a few of these filled fractures can be re-opened and become effective fractures due to the later tectonic stress. The shear fractures, which are mostly vertical, with flattened surfaces and long extension, often penetrate through the core with small aperture $(<0.5 \mathrm{~mm})$, and most of them are unfilled. Micro-fractures are usually grainpiercing-through cracks with a width of 10-100 microns, which are often re-opened along the early filled fractures (Lai et al. 2017a; Wang et al. 2016, 2018). In FMI image $\operatorname{logs}$, tectonic fractures are mainly present themselves in the group form of the parallel, echelon, broom-like, and adjustment patterns (Fig. 2), among which the parallel pattern is dominant and displayed the combination of multiple sinusoids with identical or similar shapes. The linear density of tectonic fractures interpreted by image log is generally between 0.2 and 2.3 fractures $/ \mathrm{m}$, with an average of about 0.6 fracture $/ \mathrm{m}$.

The interpretation results of image logs indicate that the tectonic fractures in the Keshen gas field include EWtrending tensile fractures and NS-trending shear fractures. Considering the structural evolution, reservoir sedimentary burial history and the results of temperature determination based on the carbon and oxygen isotopes of tectonic fracture fillings (Ding et al. 2015; Zeng et al. 2010a, b; Wang 2014), it is considered that the EW-trending tectonic fracture is suggested to be related to the Cretaceous and Paleogene regional extension, the bending and arching of the anticline, and the abnormal high pressure of Neogene. Such fractures are formed in the early stage and thus the filling rate is relatively high. The NS-trending tectonic fracture is mainly controlled by the compressive tectonic stress in the mid-late Himalayan Period along the NS-direction, and it occurs relatively late, which results in that most of them are not filled. 


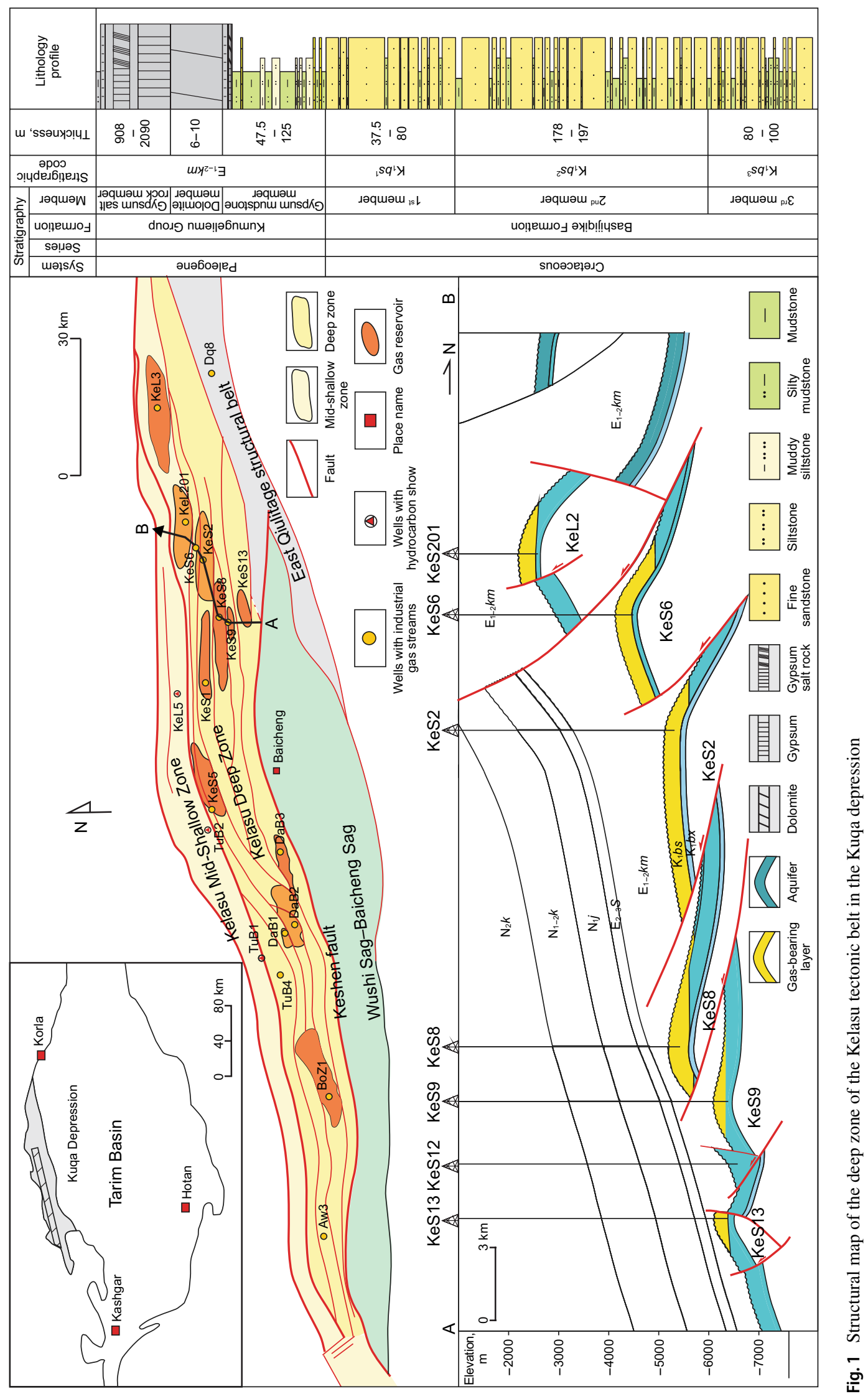




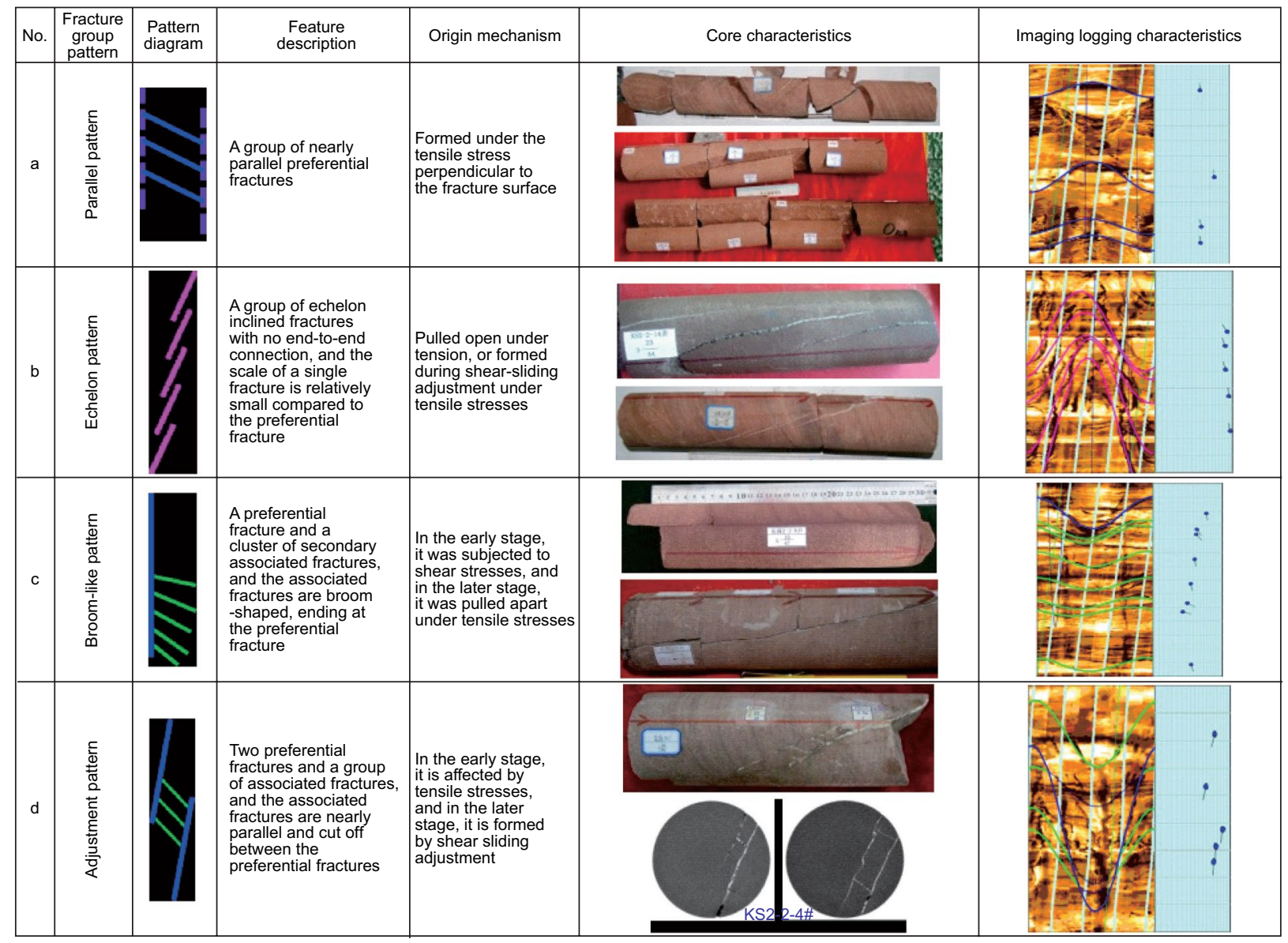

Fig. 2 Tectonic fracture characteristics of the Cretaceous Bashijiqike Formation in the Keshen gas field, the Kuqa depression

\section{Results}

\subsection{Distribution law of effective fractures}

\subsubsection{Differentiated characteristics of effective fractures in the thrust anticline}

The effective fractures are defined as factures that can permeate fluids effectively. In other words, they are fractures that have not been completely filled by minerals. Unfilled and semi-filled fractures are both effective fractures. Induced fractures and borehole breakouts, which appear at two symmetrical azimuths, are easily recognized on images and to be differentiated from natural fractures (Prioul et al. 2007; Ameen et al. 2012; Etchecopar et al. 2013; Nian et al. 2016; Ju et al. 2017; Lai et al. 2021).

Through the observation of similar outcrops in the field (Fig. 3) and the analysis of downhole measurements, it is found that the fractures in the long axis of the anticline are mostly dominated by large vertical fractures penetrating through strata. In addition, the distribution of the fractures is generally parallel to the long axis, with large fracture aperture, low filling degrees and high effectiveness. Along the two wings, the fracture density increases slightly, but the fracture aperture decreases gradually, accompanied by the growing filling degrees. Near the thrust fault, the fractures are mostly densely networked, which are often filled with the late-stage gypsum (outcrops) or calcite, dolomite and other minerals. The fracture effectiveness is inferior, and with the increasing distance to the fault, the fracture density decreases. In the north wing of the anticline, interlayer and oblique fractures often develop, with low filling degrees and good effectiveness. For instance, the filling rate of fractures found on cores from Well KeS8 at the higher part of the long axis of the KeS8 anticline is only $26 \%$, the fracture aperture is $0.275 \mathrm{~mm}$, and the linear density is 0.43 fractures $/ \mathrm{m}$, indicating a highly satisfactory fracture effectiveness. As for Well KeS801 located at the wing of the fold, the core fracture filling rate is $35 \%$, and the aperture is $0.21 \mathrm{~mm}$, while the density is 0.33 fractures/m (Fig. 4). 
Stress field modeling analysis is commonly used to unravel mechanical development of a fault-related fold (Sun et al. 2017). The magnitudes of tectonic stress were correlated with core test (Acoustic emission (AE) analysis) stress magnitudes. The numerical simulation of the curvature and stress change of the bending anticline shows when the rock is bent and deformed into the anticline shape, due to existence of a neutral plane, the strata above the neutral plane are subjected to the tensile strain, where the formed tectonic fracture is mainly tensile fractures with large aperture (Fig. 5) (Sun et al. 2017). At the same time, as these parts are located at the top of the gas reservoir, less affected by formation water, the fracture filling degree is low and the effectiveness is good, yet with a small fracture line density is small. On the other hand, the strata below the neutral plane are mainly subjected to compressive strains, where the formed fractures are mainly netted fractures with small aperture, and the nearby formation water causes high filling degrees. Therefore the effectiveness of these tectonic fractures is low, yet associated with high fracture line density (Table 1). The thickness of the tension zone on the anticline hinge and the higher part of the hinge zone is thick, and the thickness becomes thinner towards the two wings. The thickness of the tension zone near the fault or the steep south wing is large; the thickness of the gentle wing far away from the fault is relatively smaller (Fig. 6) (Sun et al. 2017).

\subsubsection{Development patterns of effective fractures}

Due to the tectonic mechanics-based origin, the spatial distribution of the longitudinal tensile fracture zone, adjustment fracture zone and netted fracture zone in the Keshen gas field is closely related to the high productivity of gas wells. The actual drilling and test data show that among the three types of fracture zones, the NS adjustment fracture zone has the strongest longitudinal extension ability and high effectiveness, followed by the EW longitudinal tensile fracture zone and at last the netted fracture zone with multiple dip angles. During the deployment of well sites, it is suggested in principle that the location deployment and completion of appraisal wells and development wells should first select the area of the NS adjustment fracture zone that communicate with the EW longitudinal tensile fracture zone (Fig. 7a), where the fracture effectiveness is high and high-rate industrial gas streams can be obtained without reservoir stimulation or with only acidizing (e.g., Well KS2-2-8). For the borehole that is confirmed later by actual drilling to encounter the relatively independent EW longitudinal tensile fracture zone (Fig. 7b), the fracture filling degree is relatively high and large-scale reservoir stimulation such as acidizing fracturing or propped fracturing are often required.

\section{Discussion}

\subsection{Main factors controlling fracture effectiveness}

Fracture effectiveness refers to the fluid seepage capacity through fractures, mainly represented by the fracture aperture and filling degrees of fractures. The effectiveness of open fractures is good, while that of filled fractures and closed fractures is poor. The comprehensive parameter of fracture effectiveness is mainly reflected by the influence of fractures on reservoir permeability, namely, fracture permeability. On the basis of the tectonic stress field simulation, with the constraints of outcrop fracture model and fracture parameters identified by core description, fracture ICT (industrial computed tomography) scanning (Lai et al. 2017b) and FMI image log of wells (Lai et al. 2018), combined with research results in lost circulation while drilling and well testing interpretation and introduction of the concept of fracture filling degrees, the three-dimensional spatial distribution of fracture effectiveness (fracture permeability) is determined (Eq. 1) (Song et al. 2001), with respect to the fracture density, aperture and filling degrees in the Keshen gas field, using the tectonic fracture-tectonic stress correlation model developed in previous studies (Wang et al. 2016). In general, the fracture permeability is in direct proportion to the fracture line density and the cube of the fracture aperture, and in inverse proportion to the filling degree. Among these parameters, the most sensitive control factor is the fracture aperture, which is mainly controlled by the structural pattern and the fracture tensile zone. The thickness of the tensile zone of the faulted anticline gradually increases with the increase in the thrust shortening rate and the decrease of the wing angle. The thickness of the transition zone and tensile zone at the southward hinge zone is larger, and the tensile zone thickness of the southern wing is larger than that of the northern wing. With the increase in the thrust shortening rate, the tensile-transition zone gradually extends from the hinge zone to both wings (Fig. 8).

$$
\left[\begin{array}{l}
K_{\mathrm{fX}} \\
K_{\mathrm{f} Y} \\
K_{\mathrm{f} Z}
\end{array}\right]=\sum_{i}^{n}\left[\begin{array}{l}
K_{\mathrm{f} X i} \\
K_{\mathrm{f} Y i} \\
K_{\mathrm{f} Z i}
\end{array}\right]=(1-C)^{3} \sum_{i}^{n} \frac{b_{\mathrm{m} i}^{3} D_{1 \mathrm{f} i}}{12}\left[\begin{array}{l}
1-n_{\mathrm{f} 1 i}^{2} \\
1-n_{\mathrm{f} 2 i}^{2} \\
1-n_{\mathrm{f} 3 i}^{2}
\end{array}\right]
$$

where $K$ is the fracture permeability; $K_{\mathrm{f} X}, K_{\mathrm{f} Y}$, and $K_{\mathrm{fZ}}$ represent the fracture permeability in three directions, respectively, $10^{-3} \mu \mathrm{m}^{2} ; K_{\mathrm{fX} i}, K_{\mathrm{f} Y i}$, and $K_{\mathrm{fZi}}$ represent the fracture permeability component in three directions, $10^{-3} \mu \mathrm{m}^{2} ; D_{\mathrm{lf}}$ is the fracture line density, fractures $/ \mathrm{m} ; C$ is the fracture filling coefficient (measured quantitatively by core observation and ICT scanning). When the fracture is not filled, $C=0$; when 


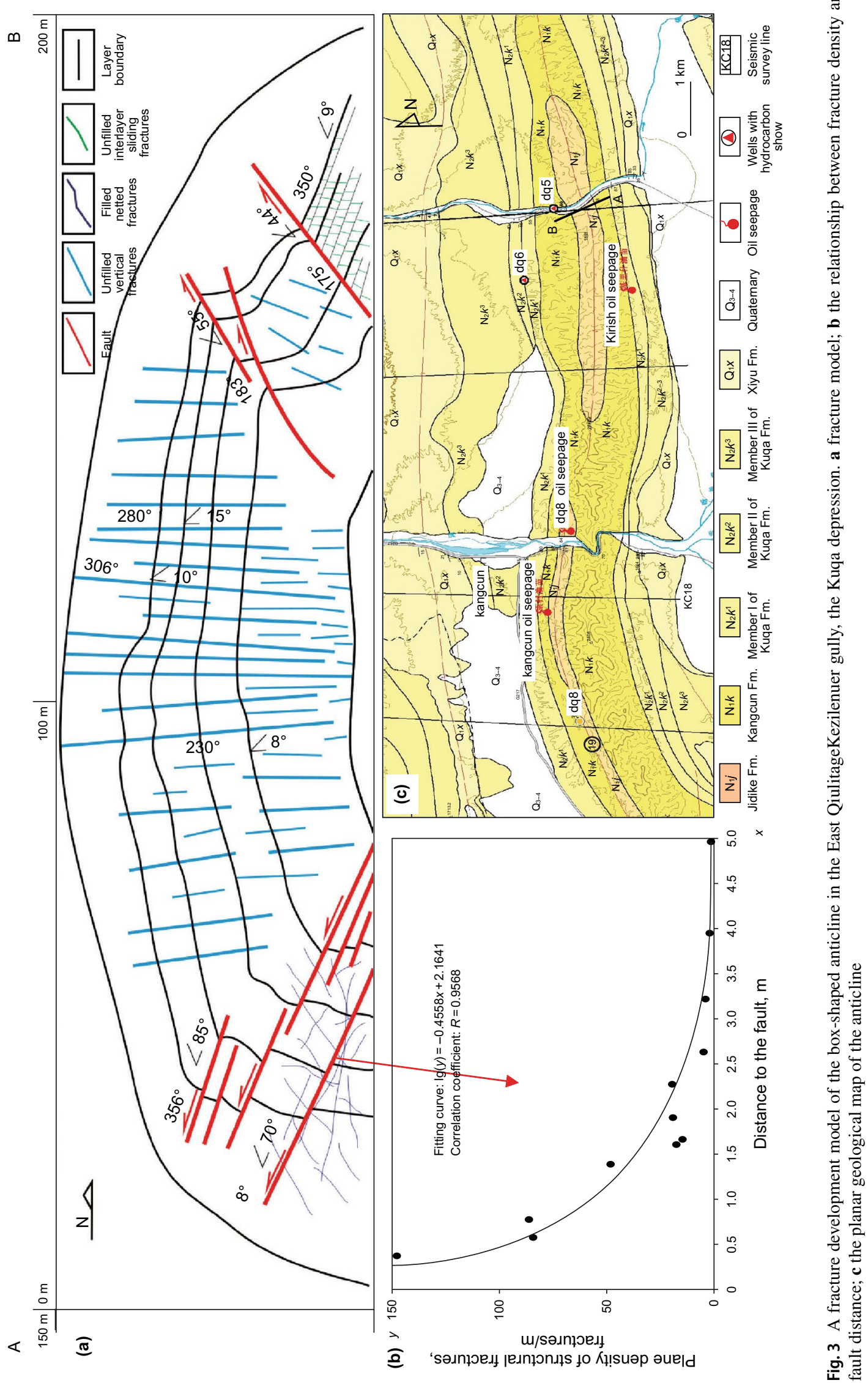


the fracture is completely filled, $C=1 . b$ is the fracture aperture, $\mathrm{mm} ; n$ is the permeability tensor (obtained from the fracture occurrence of the core observation or FMI logging).

The filling degree in different structural parts is an important factor influencing fracture effectiveness. Core observation demonstrates that fractures on the limb always have higher filling degree than that on the hinge of anticline (Fig. 4a), especially which close to the boundary faults, where the fracture filling degree can reach to $70 \%$ (Well Keshen207).

\subsection{Petroleum geological significance of effective fractures}

\subsubsection{Contributions/effects of fractures to/on reservoir storage space and permeability}

According to the ICT experimental study of fractured core, for tight sandstone reservoirs, the porosity provided by effective fractures is generally less than $0.5 \%$ (Fig. 9). Therefore, tectonic fracture usually does not exist as the main type of reservoir space, but as an efficient seepage channel, which can greatly improve the permeability of reservoir. The core measurement of Keshen gas field shows that the matrix permeability without fractures is generally $(0.01-0.1) \times$ $10^{-3} \mu \mathrm{m}^{2}$, while the permeability with fracture is generally $(1-10) \times 10^{-3} \mu \mathrm{m}^{2}$ (Fig. 10), which is $1-2$ orders of magnitude higher than the matrix permeability, and the maximum permeability of single well test is $116.5 \times 10^{-3} \mu \mathrm{m}^{2}$, proving that the effective fracture significantly improves the permeability of tight sandstone reservoir.

\subsubsection{Influence of fracture-pore-throat homogeneous network on natural gas productivity}

Core plug testing and well logging interpretation demonstrate that the matrix physical property has not significant variations in different structural belts. Therefore, the development of effective fractures in tight sandstones will become the most important factors influencing gas production (Lai et al. 2017a; Ameen et al. 2012).

The gas reservoir of the Kuqa foreland thrust belt is all associated with a faulted anticline structure. Due to the concentrated tectonic strain in the high part of anticline, tectonic fractures relatively extensively develop in the higher part, with larger aperture and lower filling degrees than those of tectonic fractures in other structural positions. The netted tectonic fracture has a good communication with reservoir matrix pores and throats, forming superior seepage channels, which are important guarantees for high and stable production. When the netted open fractures and vertical open fractures densely develop in the higher part of the structure, they communicate effectively with the reservoir matrix pores and throats (generally fine mesopores and fine throats, classified in accordance with SYT 6285-1997 Evaluating Methods of Oil and Gas Reservoirs), and thus form a fracture-porethroat seepage network system. The formation fluid pressure is balanced with the supply from fractures to the wellbore by the fluid supply from matrix rock to fracture, which leads to an apparent-homogenous to medium-heterogeneous body (Fig. 11), which can present high production and moreover long-term stable production of natural gas.

Many wells including KeS8, 801, 802, 8-1, 8-2, 8003, 8004 are of this type. The 6746-6897 m section of Well $\mathrm{KeS} 8003$ is recovered with a $10 \mathrm{~mm}$ choke after completion of acid fracturing, resulting in daily output of $113.604 \times 10^{4}$ $\mathrm{m}^{3}$. On November 12, 2013, it starts the production testing, with a daily natural gas production of $88 \times 10^{4} \mathrm{~m}^{3}$. After 54 days of production, the tubing pressure drops from 88.2 to $85.09 \mathrm{MPa}$, and the monthly pressure drop rate is 1.73 $\mathrm{MPa} /$ month, which indicates the tubing pressure is basically stable (Fig. 12). 

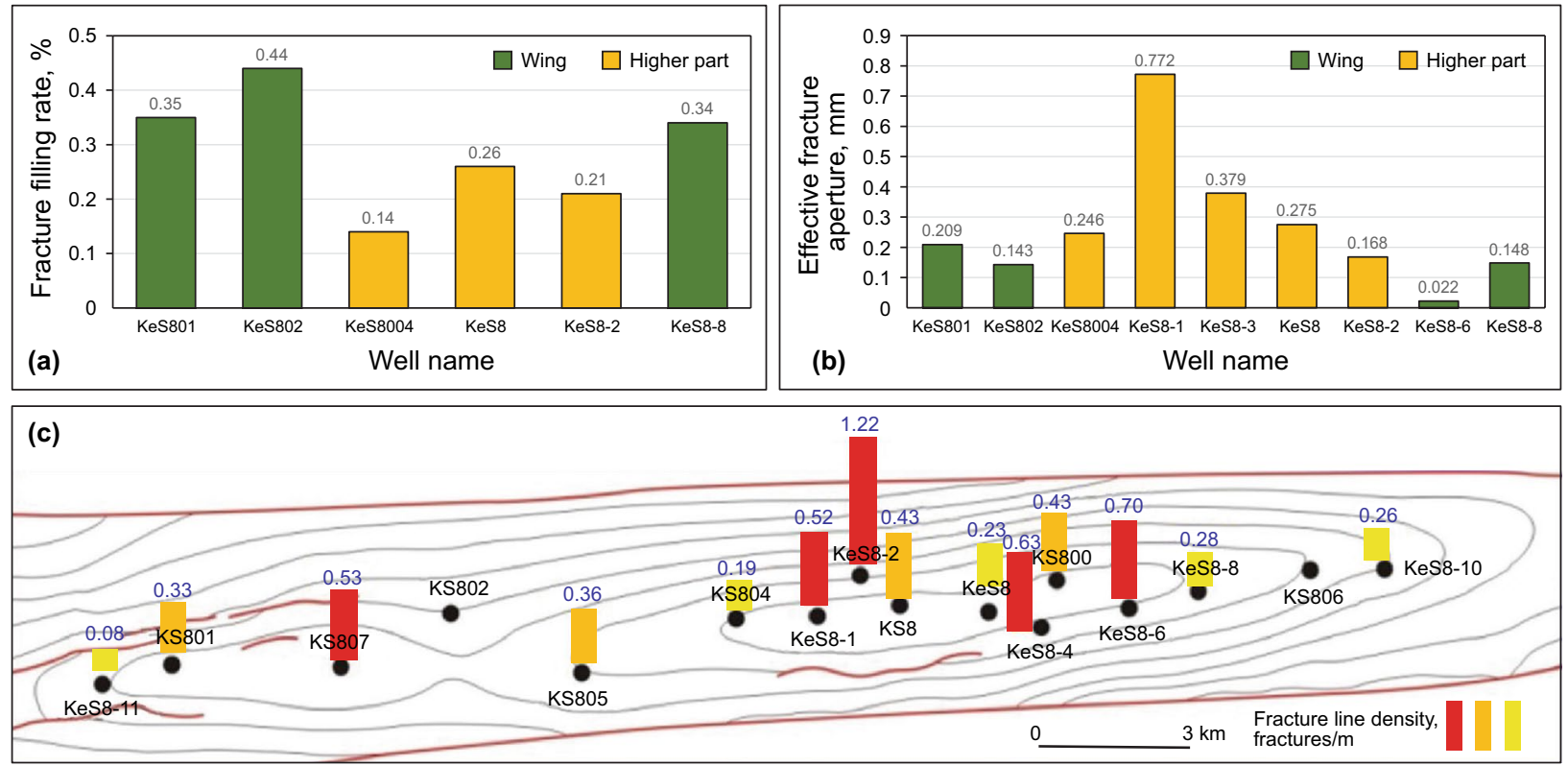

Fig. 4 Histograms showing differences of fracture characteristics at different structural locations in Block 8 of Keshen in the Kuqa depression. a fracture filling rate; $\mathbf{b}$ effective fracture aperture; $\mathbf{c}$ image log FMI-based fracture line density. The wells marked as red, orange and yellow colors correspond to the highest, higher and high gas production wells, respectively
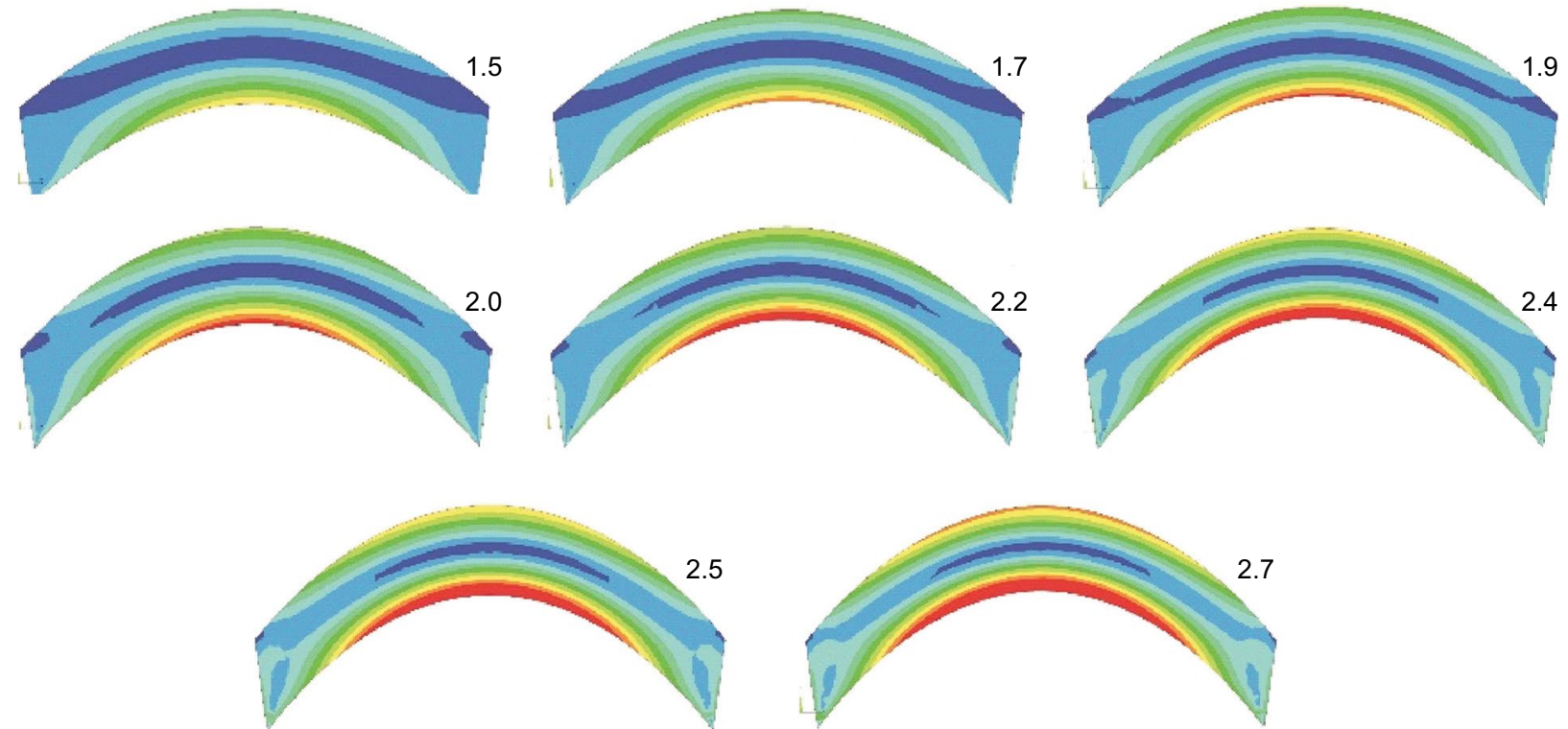

Mises stress, MPa

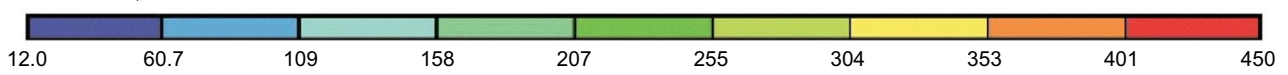

Fig. 5 Finite element simulation results of tectonic stresses in anticlines with different bending degrees 


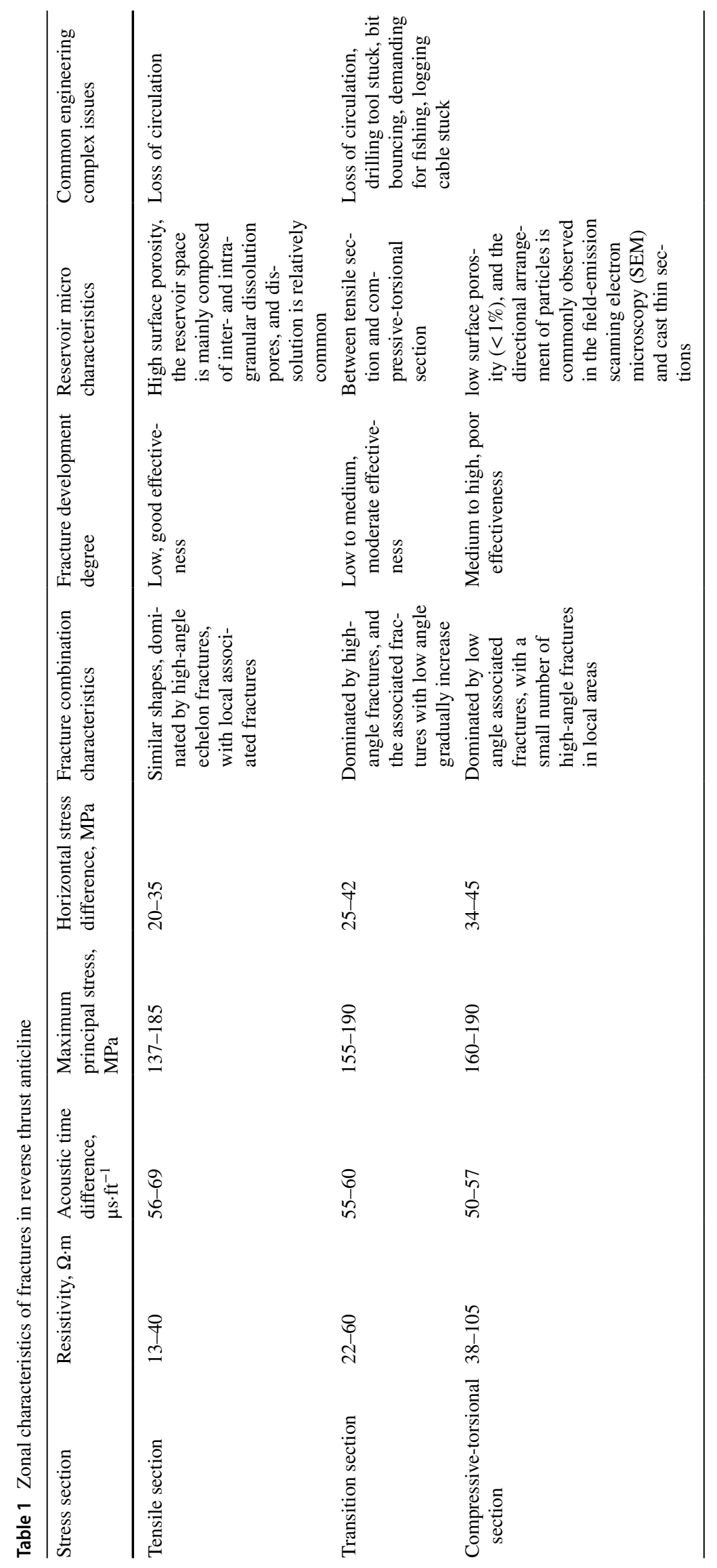




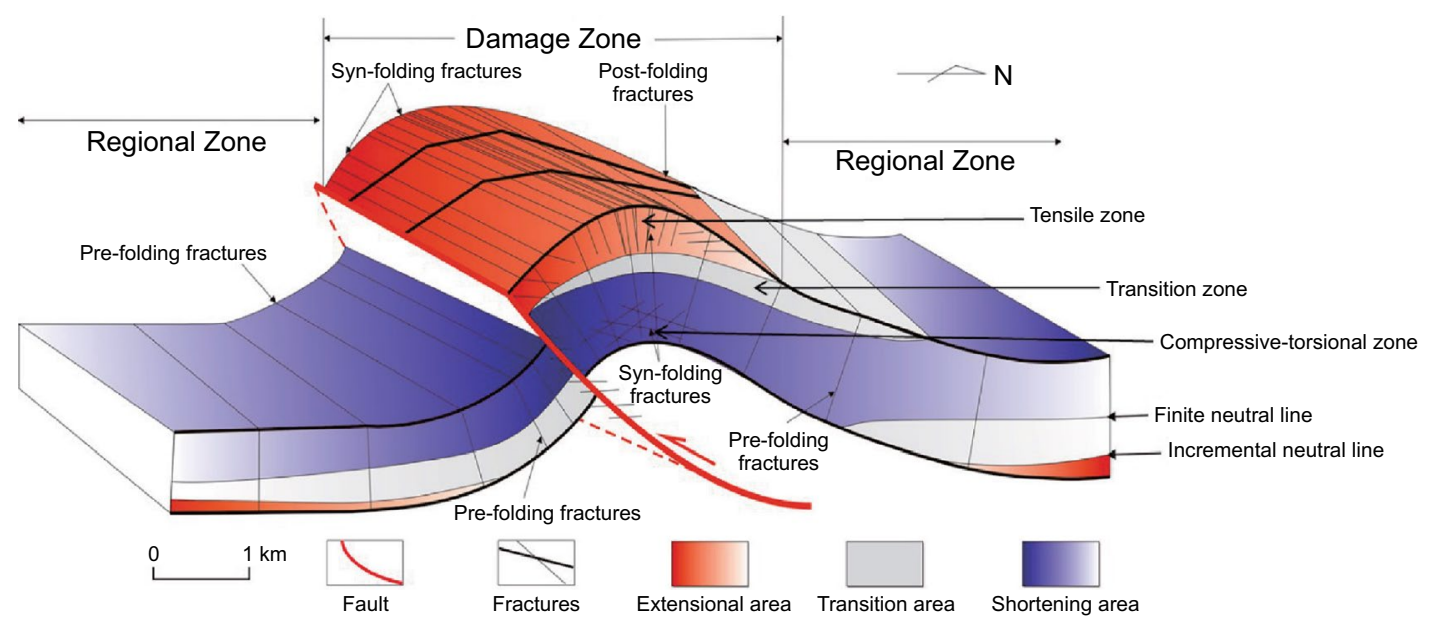

Fig. 6 Zonal fracture development patterns of the faulted anticline of the Keshen gas field, the Kuqa depression

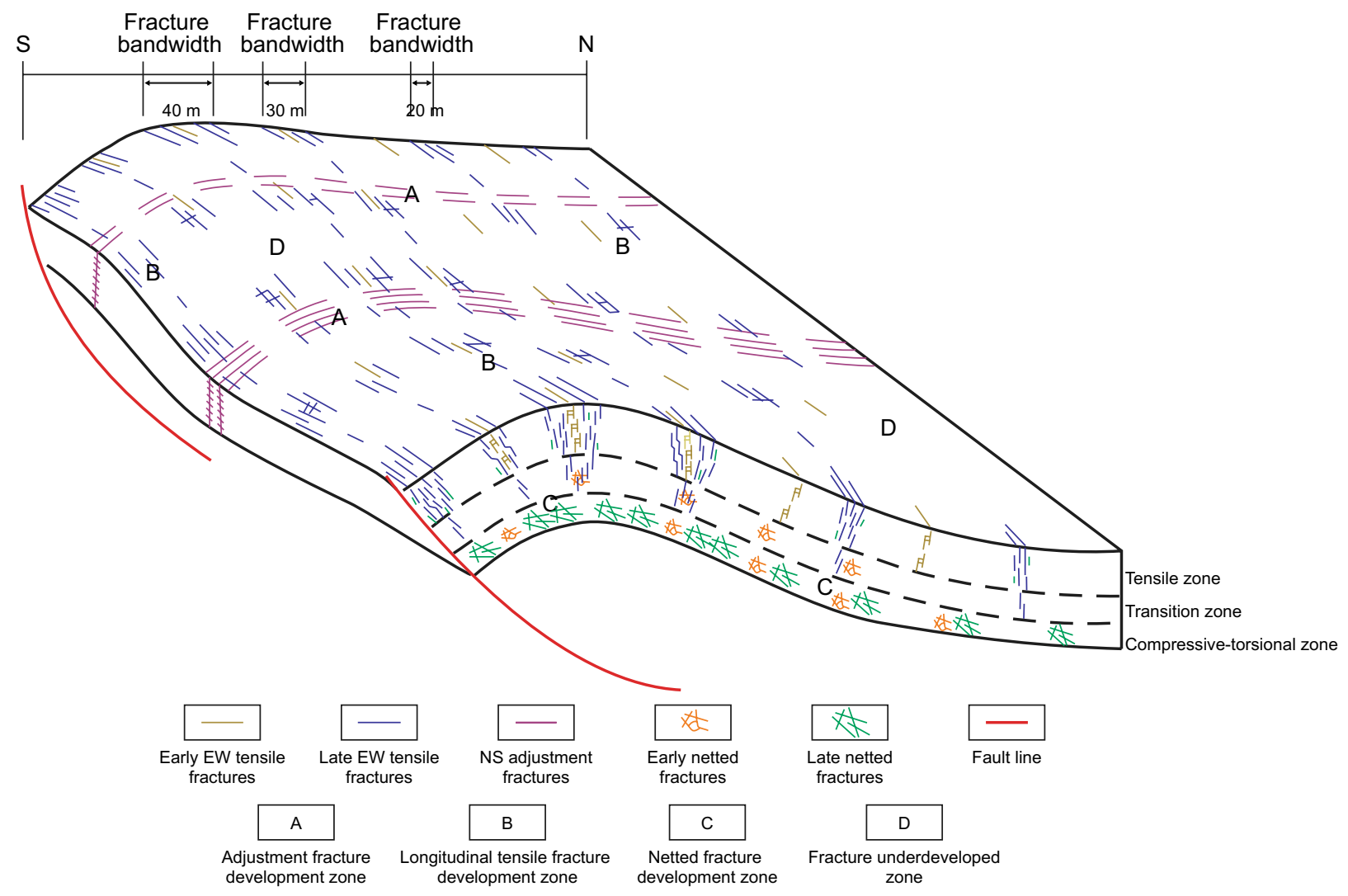

Fig. 7 The fracture zones and the development pattern of fracture effectiveness in the Bashijiqike Formation in the Keshen gas field in the foreland thrust zone of the Kuqa depression 
Shortening rate $5 \%$ Angle between two wings 1600

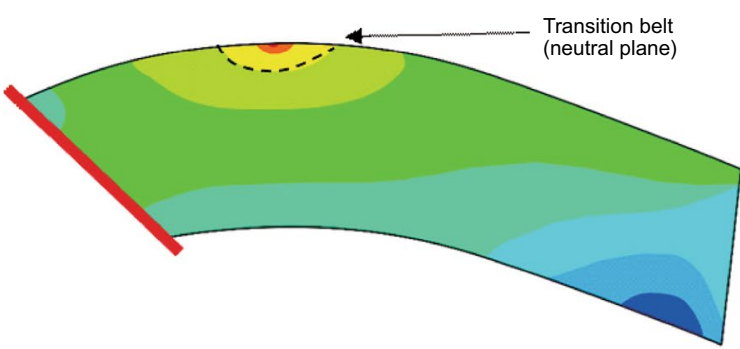

Shortening rate $15 \%$ - Angle between two wings 1200

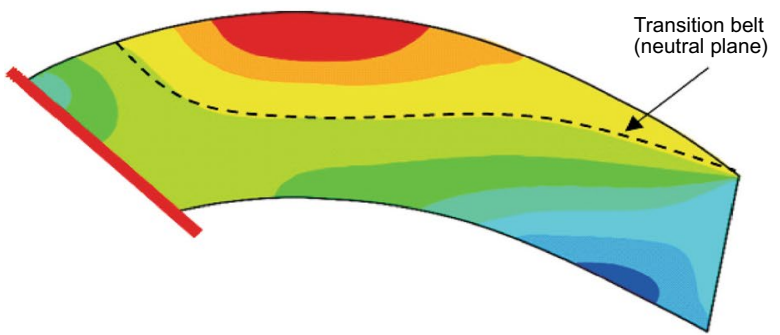

Shortening rate $10 \%$ - Angle between two wings 1400

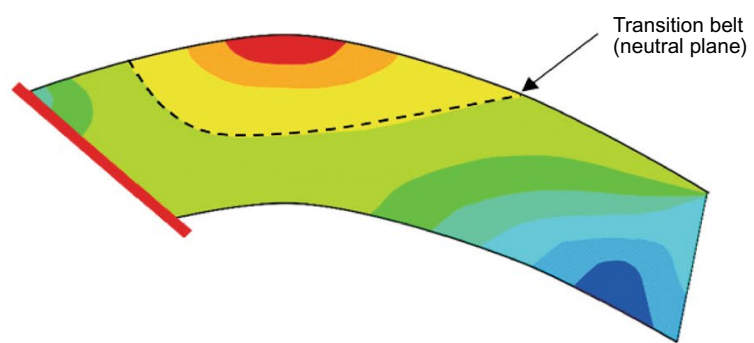

Shortening rate $20 \%$ - Angle between two wings 1000

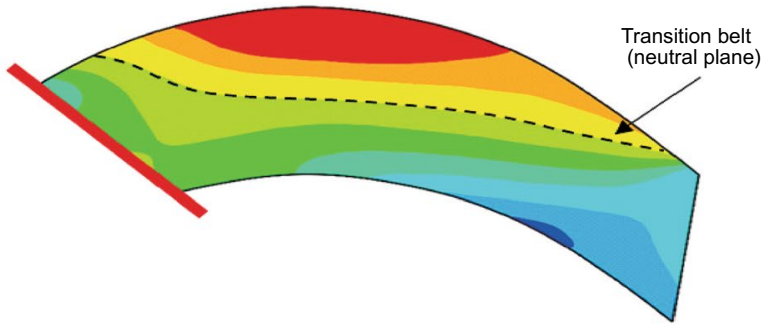

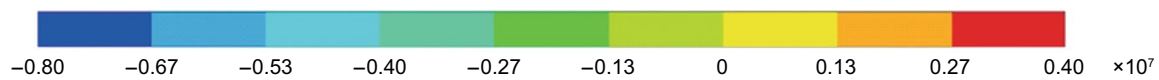

Fig. 8 Simulation diagram of dynamic evolution of the tension zone and transition zone of the Keshen gas field in the foreland thrust belt of Kuqa depression

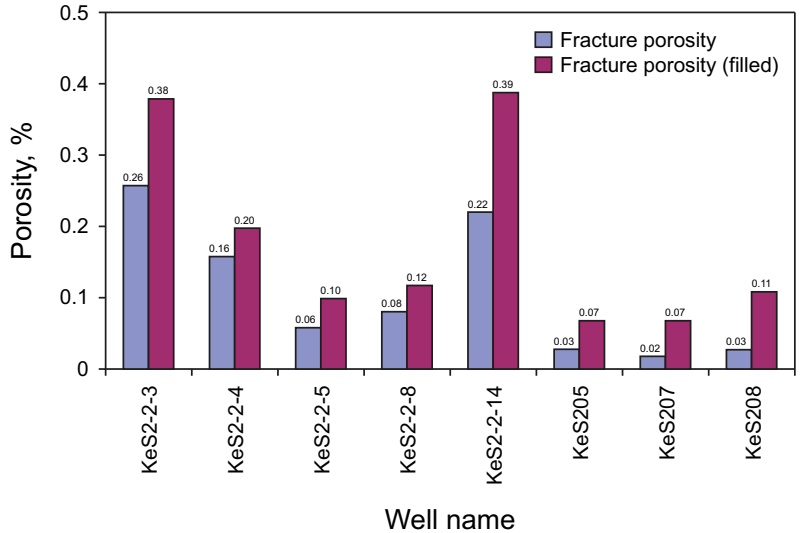

Fig. 9 Histogram of fracture porosity of the Keshen gas field in the foreland thrust zone of Kuqa depression

\section{Conclusion}

(1) Tectonic fractures in the thrust belt include EW-trending high-angle tensile fractures and nearly NS-trending vertical shear fractures. The former is related to the Cretaceous and Paleogene EW regional extension and the bending and arching of the anticline, and the fracture filling rate is relatively high. The latter is related to the NS tectonic compression in the mid-late Himalayan

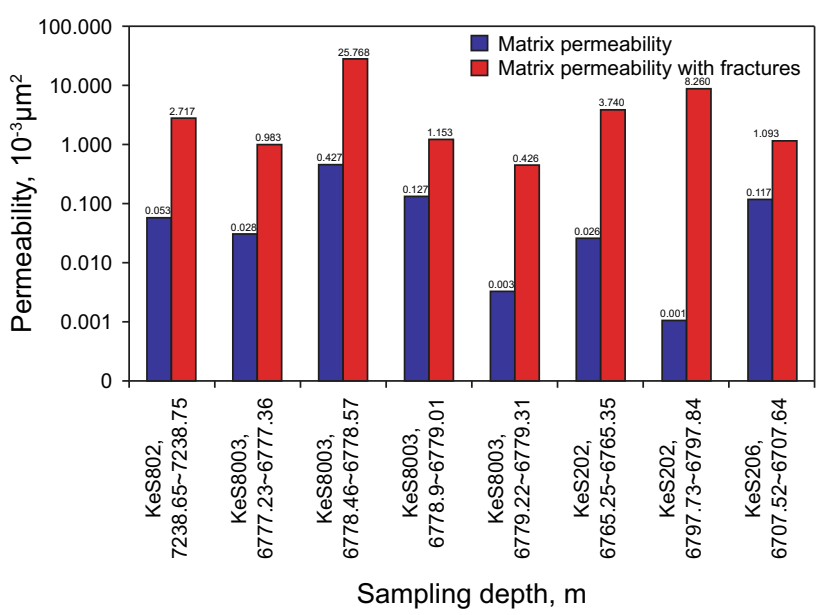

Fig. 10 Matrix permeability and fracture permeability of the Keshen gas field in the foreland thrust zone of the Kuqa depression

Period, and most of these fractures are unfilled. Microstructural cracks are usually grain-piercing-through cracks with width of 10-100 microns. In FMI image $\log$, tectonic fractures are mainly arranged in parallel.

(2) In the planar view, the effective fractures are concentrated in the high part and the wing zones of the long axis of anticline, and along the vertical direction they mainly develop in the tensile fracture zone above the neutral plane. The adjustment fracture zone has strong longitudinal extension abilities and high effectiveness, 
Fig. 11 Contributions of the reservoir fracture-pore-throat network system to hydrocarbon production in the Keshen area of the foreland thrust belt of the Kuqa depression

followed by the nearly EW longitudinal tensile fracture zone, and the netted fracture zone with multiple dip angles.

(3) Fracture effectiveness is mainly controlled by fracture density, aperture and filling degrees, among which the fracture aperture is the most critical and most sensitive factor. High fracture aperture is mainly seen in the fracture tensile zone. The tectonic fracture can directly increase permeability of the reservoir matrix by $1-2$ orders of magnitude, and increase the porosity by less than $0.5 \%$. The higher part of the thrust anticline is characterized by concentrated tensile strains, high fracture density, large aperture, low filling degrees, and thus good fracture effectiveness. Such zones are associated with high tectonic fracture permeability, which controls enrichment and high production of natural gas.

(4) When the netted open fractures and vertical open fractures densely develop in the high part of the structure, they communicate effectively with the reservoir matrix pores and throats, which forms a fracture-pore-throats seepage network system. The formation fluid pressure is balanced with the supply from fractures to the wellbore by the fluid supply from matrix rock to fracture, which leads to an apparent-homogenous to mediumheterogeneous body that is seen with high yield and long-term stable production of natural gas.

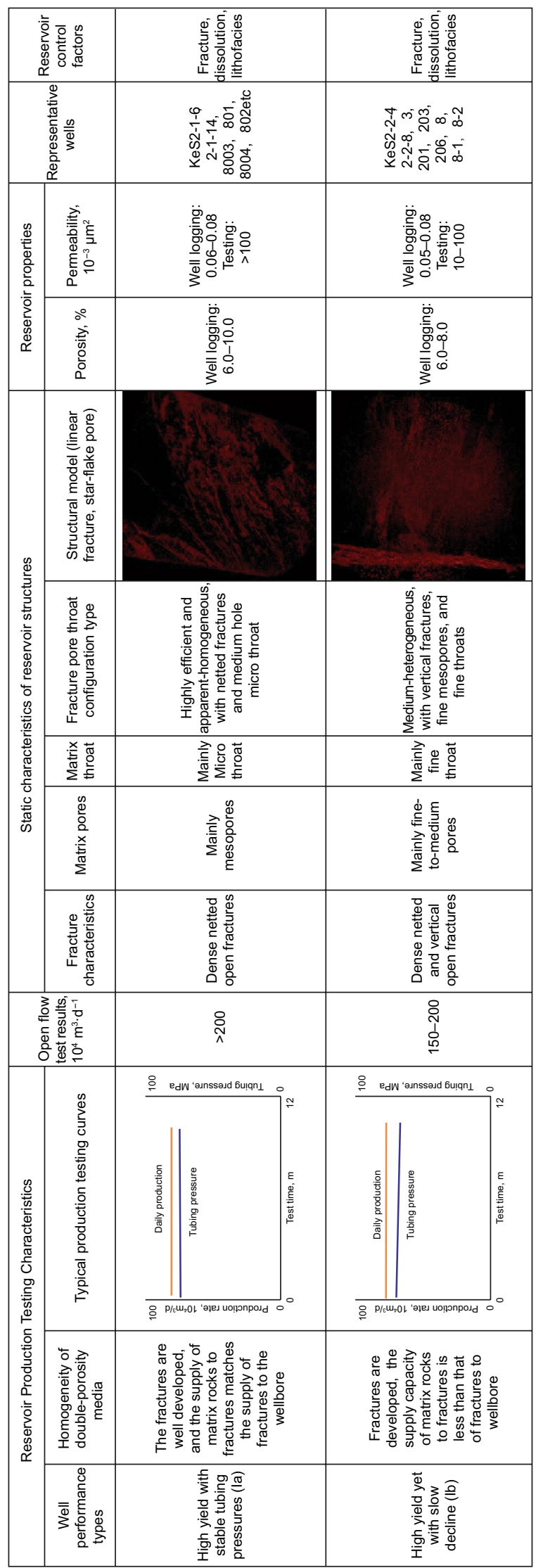




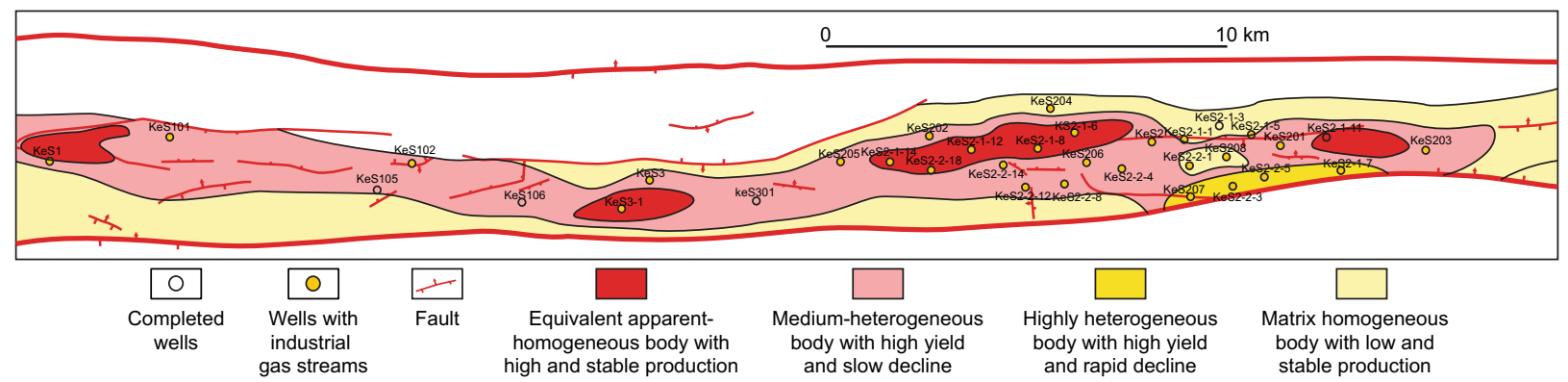

Fig. 12 Distribution of high-production stable-production zones in Block 2, the Keshen area, the foreland thrust belt, the Kuqa depression

\begin{abstract}
Acknowledgements This work was supported by the National Key Research and Development Project (No. 2019YFC0605501) and the National Science and Technology Major Project (2016ZX05003001). The authors would like to thank PetroChina Tarim Oilfield Company for their assistance in providing data. We thank the editors of Petroleum Science and the reviewers, whose constructive comments improve the paper.
\end{abstract}

Open Access This article is licensed under a Creative Commons Attribution 4.0 International License, which permits use, sharing, adaptation, distribution and reproduction in any medium or format, as long as you give appropriate credit to the original author(s) and the source, provide a link to the Creative Commons licence, and indicate if changes were made. The images or other third party material in this article are included in the article's Creative Commons licence, unless indicated otherwise in a credit line to the material. If material is not included in the article's Creative Commons licence and your intended use is not permitted by statutory regulation or exceeds the permitted use, you will need to obtain permission directly from the copyright holder. To view a copy of this licence, visit http://creativecommons.org/licenses/by/4.0/.

\section{References}

Ameen MS, MacPherson K, Al-Marhoon MI, et al. Diverse fracture properties and their impact on performance in conventional and tight-gas reservoirs, Saudi Arabia: The Unayzah, South Haradh case study. AAPG Bull. 2012;96(3):459-92. https://doi.org/10. 1306/06011110148.

Chang LJ, Zhao LB, Yang XJ, et al. Application of industrial computed tomography (ICT) to research of fractured tight sandstone gas reservoirs. Xinjiang Pet Geol. 2014;35(4):471-5 (in Chinese).

Dai JX, Ni YY, Wu XQ. Tight gas in China and its significance in exploration and exploitation. Pet Explor Dev. 2012;39(3):257-64. https://doi.org/10.1016/S1876-3804(12)60043-3. (in Chinese).

Ding WL, Yin S, Wang XH, et al. Assessment method and characterization of tight sandstone gas reservoir fractures. Earth Sci Front. 2015;22(4):173-87 (in Chinese). https://doi.org/10.13745/j.esf. 2015.04.019.

Etchecopar A, Yamada T, Cheung P. Borehole images for assessing present day stresses. Bulletin De La Société Géologique De France. 2013;184(4-5):307-18. https://doi.org/10.2113/gssgfbull. 184.4-5.307.

Feng J, Ren Q, Xu K. Quantitative prediction of fracture distribution using geomechanical method within Kuqa Depression, Tarim Basin, NW China. J Petrol Sci Eng. 2018;162:22-34. https://doi. org/10.1016/j.petrol.2017.12.006.
Fossen H. Deformation bands formed duraing soft-sediment deformation: observations from SE Utah. Mar Pet Geol. 2010;27(1):21522. https://doi.org/10.1016/j.marpetgeo.2009.06.005.

Gong L, Zeng LB, Du YJ, et al. Influences of structural diagenesis on fracture effectiveness: a case study of the Cretaceous tight sandstone reservoirs of Kuqa foreland basin. J China Univ Min Technol. 2015;44(3):514-9 (in Chinese). https://doi.org/10.13247/j. cnki.jcumt.000263.

Guo YC, Pang XQ, Chen DX, et al. Progress of research on hydrocarbon accumulation of tight sand gas and several issues for concerns. Oil Gas Geol. 2013;34(6):717-24 (in Chinese). https://doi. org/10.11743/ogg20130601.

Jia C, Zheng M, Zhang YF. Unconventional hydrocarbon resources in China and the prospect of exploration and development. Pet Explor Dev. 2012;39(2):129-36. https://doi.org/10.1016/S18763804(12)60026-3 (in Chinese).

Ju W, Hou GT, Zhang B. Insights into the damage zones in fault-bend folds from geomechanical models and field data. Tectonophysics. 2014;610:182-94. https://doi.org/10.1016/j.tecto.2013.11.022.

Ju W, Shen J, Qin Y, et al. In-situ stress state in the Linxing region, eastern Ordos Basin, China: implications for unconventional gas exploration and production. Mar Pet Geol. 2017;86:66-78. https:// doi.org/10.1016/j.marpetgeo.2017.05.026.

$\mathrm{Ju}$ W, Wang K. A preliminary study of the present-day in-situ stress state in the Ahe tight gas reservoir, Dibei Gasfield, Kuqa Depression. Mar Pet Geol. 2018;96:154-65. https://doi.org/10.1016/j. marpetgeo.2018.05.036.

Kara L, Joseph M, Linda M, et al. Controls on reservoir quality in exhumed basins - an example from the Ordovician sandstone, Illizi Basin. Algeria Mar Pet Geol. 2017;80:203-27. https://doi. org/10.1016/j.marpetgeo.2016.11.011.

Lai J, Wang GW, Fan ZY, et al. Fracture detection in oil-based drilling mud using a combination of borehole image and sonic logs. Mar Pet Geol. 2017a;84:195-214. https://doi.org/10.1016/j.marpetgeo. 2017.03.035.

Lai J, Wang GW, Fan ZY, et al. Three-dimensional quantitative fracture analysis of tight gas sandstones using industrial computed tomography. Sci Rep. 2017b;7:1825. https://doi.org/10.1038/ s41598-017-01996-7.

Lai J, Wang GW, Wang S, et al. A review on the applications of image logs in structural analysis and sedimentary characterization. Mar Pet Geol. 2018;95:139-66. https://doi.org/10.1016/j.marpetgeo. 2018.04.020.

Lai J, Li D, Wang GW, et al. Earth stress and reservoir quality evaluation in high and steep structure: the lower cretaceous in the Kuqa Depression, Tarim Basin. China Mar Pet Geol. 2019;101:43-54. https://doi.org/10.1016/j.marpetgeo.2018.11.036.

Lai J, Wang S, Zhang CS, et al. Spectrum of pore types and networks in the deep Cambrian to Lower Ordovician dolostones in Tarim 
Basin, China. Mar Pet Geol. 2020;112:104081. https://doi.org/10. 1016/j.marpetgeo.2019.104081.

Lai J, Chen KJ, Xin Y, et al. Fracture characterization and detection in the deep Cambrian dolostones in the Tarim Basin, China: Insights from borehole image and sonic logs. J Pet Sci Eng. 2021;196:107659. https://doi.org/10.1016/j.petrol.2020.107659.

Lander RH, Laubach SE. Insights into rates of fracture growth and sealing from a model for quartz cementation in fractured sandstones. Geol Soc Am Bull. 2015;127(3-4):516-38. https://doi. org/10.1130/B31092.1.

Li YJ, Li JB, Yang RC, et al. Relationship between gas bearing capacity and reservoir fractures of tight sand reservoirs in the eastern Block 2 of the Sulige gas field. Nat Gas Ind. 2012;32(6):28-30 (in Chinese). https://doi.org/10.3787/j.issn.1000-0976.2012.06.006.

Liu C, Zhang RH, Zhang HL, et al. Genesis and reservoir significance of multi-scale natural fractures in Kuqa foreland thrust belt, Tarim Basin, NW China. Pet Explor Dev. 2017;44(3):469-78 (in Chinese). https://doi.org/10.1016/S1876-3804(17)30057-5.

Nian T, Wang GW, Xiao CW, et al. The in situ stress determination from borehole image logs in the Kuqa Depression. J Nat Gas Sci Eng. 2016;34:1077-84. https://doi.org/10.1016/j.jngse.2016.08. 005 .

Nian T, Wang GW, Song HY. Open tensile fractures at depth in anticlines: a case study in the Tarim basin, NW China. Terra Nova. 2017;29(3):183-90. https://doi.org/10.1111/ter.12261.

Prioul R, Donald A, Koepsell R, et al. Forward modeling of fractureinduced sonic anisotropy using a combination of borehole image and sonic logs. Geophysics. 2007;72(4):135-47. https://doi.org/ 10.1190/1.2734546.

Laubach SE, Eichhubl P, Hargrove P, et al. Fault core and damage zone fracture attributes vary along strike owing to interaction of fracture growth, quartz accumulation, and differing sandstone composition. J Struct Geol. 2014;68(Part A):207-26. https://doi. org/10.1016/j.jsg.2014.08.007.

Solum JG, Davatzes NC, Lockner DA. Fault-related clay authigenesis along the Moab Fault: Implications for calculations offault rock composition and mechanical and hydrologic fault zone properties. J Struct Geol. 2010;32(12):1899-911. https://doi.org/10.1016/j. jsg.2010.07.009.

Song HZ, Jia CZ, Ouyang J. Theory and methods of fractured reservoirs. Beijing: Petroleum Industry Press; 2001. (in Chinese).

Wang K, Zhang HL, Zhang RH, et al. Characteristics and influencing factors of ultra-deep tight sandstone reservoir structural fracture: a case study of Keshen- 2 gas field, Tarim Basin. Acta Petrolei Sinica. 2016;37(6):715-27. https://doi.org/10.1016/j.jsg.2017.10. 005 (in Chinese)

Wang JP, Zhang HL, Zhang RH, et al. Enhancement of ultra-deep tight sandstone reservoir quanlity by fractures: a case of Keshen gas field of Kuqa depression. Oil Gas Geol. 2018;39(1):77-88 (in Chinese). https://doi.org/10.11743/ogg20180108.

Wang ZM. Formation mechanism and enrichment regularities of Kelasu subsalt deep large gas field in Kuqa depression, Tarim Basin. Nat Gas Geosci. 2014;25(2):153-66 (in Chinese). https:// doi.org/10.11764/j.issn.1672-1926.2014.02.0153.

Yang HJ, Zhang RH, Yang XZ, et al. Characteristics and reservoir improvement effect of structural fracture in ultra-deep tight sandstone reservoir: a case study of Keshen gas field, Kuga Depression, Tarim Basin. Nat Gas Geosci. 2018;29(7):942-50 (in Chinese). https://doi.org/10.11764/j.issn.1672-1926.2018.06.018.

Zeng LB. Fractures in sandstone reservoirs with ultra-low permeability: a case study of the Upper Triassic Yanchang Formation in the Ordos Basin, China. AAPG Bull. 2009;93(4):461-77. https://doi. org/10.1306/09240808047.

Zeng LB, Gong L, Zu KW, et al. Influence factors on fracture validity of the Paleogene reservoir, western Qaidam Basin. Acta Geol Sin. 2012;86(11):1809-14 (in Chinese).

Zeng LB, Ke SZ, Liu Y. Study methods of fractures in low-permeability oil-gas reservoirs. Beijing: Petroleum Industry Press; 2010a. p. 1-187 (in Chinese).

Zeng LB, Qi JF, Wang CG, et al. The influence of tectonic stress on fracture formation and fluid flow. Earth Sci Front. 2008;15(3):292-8 (in Chinese). https://doi.org/10.3321/j.issn: 1005-2321.2008.03.026.

Zeng LB, Tan CX, Zhang ML. Tectonic stress field and its effect on hydrocarbon migration and accumulation in Mesozoic and Cenozoic in the Kuqa Depression, Tarim Basin. Sci China Ser D Earth Sci. 2004;34(S1):98-106. https://doi.org/10.1360/04zd0030.

Zeng LB, Wang HJ, Gong L, et al. Impacts of the tectonic stress field on natural gas migration and accumulation: a case study of the Kuqa Depression in the Tarim Basin, China. Mar Pet Geol. 2010b;27:1616-27. https://doi.org/10.1016/j.marpetgeo.2010.04. 010.

Zhang RH, Yang HJ, Wang JP, et al. The formation mechanism and exploration significance of ultra-deep, low-permeability and tight sandstone reservoirs in Kuqa depression, Tarim Basin. Acta Petrolei Sinica. 2014;35(6):1057-69 (in Chinese). https://doi.org/10. 7623/syxb201406003.

Zhang ZP, Wang QC. Characteristics of joint and shear fractures and its indication on regionalstress field transfer. Sci China Ser D Earth Sci. 2004;34(suppI):63-73. https://doi.org/10.3969/j.issn.16747240 (in Chinese).

Zhao JL, Wang JP, Liu C, et al. Reservoir fracture numerical simulation of Keshen-2 Block in Tarim Basin. Geoscience. 2014;28(6):127583 (in Chinese). https://doi.org/10.3969/j.issn.1000-8527.2014. 06.019 . 